\title{
Sustentabilidade do endividamento estudantil em uma macrodinâmica liderada pela demanda *
}

\author{
Gustavo Pereira Serra \\ Gilberto Tadeu Lima ${ }^{* * *}$
}

\begin{abstract}
Resumo
Este artigo analisa a sustentabilidade do endividamento estudantil em um modelo teórico no qual o nível de atividade econômica é determinado pela demanda efetiva agregada. Enquanto grande parte da literatura sobre dívida estudantil considera em sua avaliação de sustentabilidade apenas os diferenciais de salário entre trabalhadores com níveis de escolaridade distintos, propõe-se uma metodologia formal que compreenda os impactos desse endividamento sobre determinadas variáveis macroeconômicas que influenciam a capacidade de pagamento dessa dívida, tais como a taxa de emprego. São comparadas duas formas de pagamento da dívida, sendo a primeira similar aos Income-Driven Repayment Plans, recentemente comuns nos Estados Unidos, e a segunda a propensão marginal a consumir das famílias que se adapta, em alguma medida, ao serviço da dívida. O resultado obtido indica que fatores como a distribuição da renda e as propensões marginais a consumir de diferentes classes funcionais têm impacto sobre as condições macroeconômicas para a sustentabilidade desse endividamento.
\end{abstract}

Palavras-chave: Dívida estudantil; Distribuição de renda; Regimes Minskyanos de financiamento; Macrodinâmica; Demanda efetiva agregada.

\begin{abstract}
\section{Sustainability of student debt in demand-led macrodynamics}

This paper analyzes the sustainability of student debt in a theoretical model in which economic activity is determined by aggregate effective demand. While most of the literature on this topic only considers the wage differentials among workers with distinct educational levels, we propose a formal methodology that considers the impact of this indebtedness on certain macroeconomic variables that affect the possibility of serving the outstanding debt, such as the rate of employment. We compare two forms of debt repayment, the first being similar to the "Income-Driven Repayment Plans", which have become common in the U.S. as of late, while, in the second, households' marginal propensity to consume adapts, to some extent, to the debt service. Our results indicate that factors such as the distribution of income and marginal propensities to consume of different functional classes affect the macroeconomic conditions related to the sustainability of student debt.
\end{abstract}

Keywords: Student debt; Income distribution, Minskyan financing regimes; Macrodynamics; Effective aggregate demand.

JEL E12, E23, E25.

*Artigo recebido em 29 de setembro de 2016 e aprovado em 26 de maio de 2017. Os autores agradecem a Laura Barbosa de Carvalho, Fernando Monteiro Rugitsky, Júlia Burle Gonçalves, Guilherme Klein Martins, Gustavo Chagas Goudard e dois pareceristas anônimos deste periódico por seus comentários e sugestões, eximindo-os de responsabilidade por eventuais erros e imprecisões.

** Mestre em Teoria Econômica pelo Departamento de Economia da Faculdade de Economia, Administração e Contabilidade da Universidade de São Paulo (FEA-USP), São Paulo, SP, Brasil. E-mail: gserra@usp.br.

**** Professor do Departamento de Economia da FEA-USP, São Paulo, SP, Brasil. E-mail: giltadeu@ usp.br. 


\section{Introdução}

Os efeitos da escolarização sobre os rendimentos do trabalho são verificados por diferentes estudos (Becker, 1964; Card, 1999). Em particular, o ensino superior apresenta impacto significativo sobre a remuneração do indivíduo com esse nível de escolaridade (Carneiro; Heckman; Vytlacil, 2011). Todavia, a elevação dos custos em cursar o ensino superior, verificada, sobretudo, nos últimos anos, em diversos países, representa um fator relevante para a decisão do indivíduo sobre realizar o investimento em seu nível de escolaridade ${ }^{1}$. Dada essa barreira pecuniária, cria-se um possível círculo vicioso de elevação da desigualdade salarial: somente as famílias com rendimentos elevados poderiam arcar com o custo da educação superior, eventualmente aumentando sua remuneração do trabalho e ampliando ainda mais a desigualdade salarial. Nesse sentido, o financiamento estudantil apresenta papel importante, ao permitir que indivíduos com rendimentos insuficientes para arcar com esses custos cursem o ensino superior.

A lógica do financiamento estudantil é que os retornos salariais esperados, decorrentes dessa elevação da escolaridade, serão superiores ao custo da educação, dado um horizonte de tempo significativo. Assim, embora esse endividamento seja elevado em comparação aos rendimentos presentes do indivíduo beneficiado pelo crédito estudantil, o retorno financeiro esperado tornaria essa dívida sustentável (Dynarski; Kreisman, 2013). Segundo essa abordagem, a análise sobre o endividamento estudantil deveria se basear apenas na comparação entre o custo do investimento em educação e o valor presente dos benefícios que geraria, como uma elevação dos rendimentos do trabalho (Avery; Turner, 2012; Akers; Chingos, 2014b). Autores que consideram, em sua análise, fatores tais como o nível de emprego, dentre eles Oreopoulos e Salvanes (2011), tratam-no simplesmente no que tange às diferentes taxas de desemprego relacionadas a níveis de escolaridade distintos.

No entanto, essas formas de abordar a questão, seja analisando somente os diferenciais de salário esperados, seja assumindo como dadas as condições de empregabilidade, tipicamente negligenciam o impacto do próprio nível do endividamento estudantil sobre várias condições macroeconômicas e, consequentemente, em uma macrodinâmica liderada pela demanda agregada sobre a taxa de emprego. Vale ressaltar que, caso esse endividamento estudantil seja elevado em comparação ao total de famílias da economia, podem existir consequências negativas dessa própria dívida e do pagamento de seus encargos sobre as taxas de emprego e de salário real dessa economia e, consequentemente, sobre a capacidade de pagamento do empréstimo estudantil. O canal de transmissão desse efeito ocorre por meio do consumo das famílias: como será analisado detalhadamente nas próximas seções, o pagamento do serviço da dívida pelas famílias implica uma

(1) Para o caso dos Estados Unidos, esse resultado pode ser observado, por exemplo, em College Board (2015). 
redução de seu consumo e, consequentemente, da demanda agregada $^{2}$. Sob determinadas condições a serem mapeadas e devidamente analisadas, formal e substantivamente, essa redução na demanda agregada apresenta impacto negativo sobre o nível de emprego e sobre a renda dos trabalhadores, afetando desfavoravelmente a sua própria capacidade de pagamento da dívida.

Dessa maneira, o objetivo do presente artigo é incluir a questão dos impactos do endividamento estudantil sobre a taxa de emprego, de modo a contribuir com a análise da sustentabilidade dessa dívida. Porém, embora nosso foco não recaia sobre os diferenciais de salário esperados, como é a tônica na literatura tradicional, no modelo aqui desenvolvido o salário real, ainda que seja homogêneo, pode variar endogenamente ao longo do tempo como resultado de um conflito distributivo, um aspecto completamente ausente na literatura tradicional sobre endividamento estudantil reportada representativamente acima.

Na Seção 1 serão apresentadas algumas evidências empíricas sobre a dívida relacionada a empréstimos estudantis nos Estados Unidos. Todavia, vale ressaltar que a menção a esses dados tem como único propósito apresentar uma motivação à elaboração deste artigo. Ao demonstrar as ordens de magnitude do fato analisado, objetiva-se argumentar em favor da relevância do tema. Dessa forma, ressalta-se que o modelo macroeconômico, que será apresentado na Seção 3, não terá como finalidade replicar determinada economia, nem analisar a sustentabilidade do endividamento estudantil no caso específico dos Estados Unidos. A elaboração do modelo naquela seção tem por intuito somente verificar implicações lógico-teóricas de determinadas condições macroeconômicas sobre a sustentabilidade desse endividamento e, reciprocamente, o efeito do serviço dessa dívida sobre aquelas condições macroeconômicas, através de seu impacto sobre a demanda efetiva agregada. Entretanto, essas implicações recíprocas, dado sua robustez lógico-teórica, contam com uma dosagem considerável de generalidade e, portanto, certamente fornecem mais um aporte de conhecimento relevante em análises de experiências concretas em âmbito nacional e/ou de programas específicos, tais como o Fundo de Financiamento Estudantil (FIES), um programa do Ministério da Educação do Brasil.

Em termos de alocação da renda do trabalho dos devedores, a dinâmica da dívida será residual em relação ao consumo. Essa alternativa garante que, mesmo em situações nas quais o custo com o serviço da dívida é demasiadamente elevado, o nível de consumo dos trabalhadores é estritamente positivo. Na transição do curto para o longo prazo, por sua vez, serão consideradas duas situações. Na primeira, a propensão marginal a consumir sobre a renda é constante, considerando-se também a existência de um conflito distributivo para a definição do salário dos trabalhadores.

(2) A magnitude desse efeito é função, entre outras variáveis, da diferença entre a fração da renda destinada ao pagamento do serviço dessa dívida e a parcela reinjetada na economia sob forma de demanda pela classe que se apropria desse serviço. 
Apenas para fins de ilustração, uma correspondência empírica a essa hipótese para a propensão marginal a consumir é observada nos Estados Unidos para os empréstimos estudantis definidos como Income-Driven Repayment Plans, nos quais a parcela da renda dos estudantes destinada ao pagamento dos juros e da amortização da dívida é constante, podendo ser de $10 \%, 15 \%$ ou $20 \%$ da renda discricionária. No modelo do presente artigo, portanto, embora não se pretenda replicar, por impossibilidade, as várias situações específicas de nenhum país em particular, representa-se um plano de repagamento da dívida relativamente semelhante aos Income-Driven Repayment Plans existentes nos Estados Unidos (e, posteriormente, comparando-o a uma forma padrão, para então analisar os efeitos teóricos dessas duas formas de pagamento sobre a sustentabilidade do endividamento estudantil). Na segunda situação, diferentemente da literatura sobre endividamento em geral dos trabalhadores, analisa-se o comportamento da propensão marginal a consumir dos trabalhadores na dinâmica para além do curto prazo. Especificamente falando, essa propensão é afetada por variações endógenas no serviço da dívida, definindo-se uma parcela mínima da renda que deverá ser consumida pelos trabalhadores. Nessa alternativa, as famílias devem arcar, em cada curto prazo, com o pagamento dos juros e com a amortização de determinada porcentagem da dívida, havendo a possibilidade de que seus rendimentos sejam inferiores ao serviço da dívida.

Em função da enorme quantidade de fatores que podem ser analisados para diferentes formas de repagamento do endividamento estudantil (tratadas nas Seções 4 e 5), este artigo não abordará a possibilidade de novos investimentos em capital humano financiados por novos empréstimos estudantis. No entanto, apesar de não considerar a possibilidade de novos empréstimos estudantis, mas apenas a eventual rolagem de empréstimos novos concedidos até o início da história do modelo, considera-se que um estudo sobre o atual nível de endividamento estudantil e suas formas de repagamento já representa uma contribuição à literatura sobre o tema, dada a magnitude dessa dívida em países como os Estados Unidos. Na Seção 2 será realizado um breve, porém representativo, resgate da literatura sobre dívida das famílias, ressaltando-se a contribuição deste artigo àquela.

\section{Evidências empíricas sobre endividamento estudantil}

Ao final de 2014, o saldo dos empréstimos estudantis totalizou US\$ 1,2 trilhão nos Estados Unidos, com crescimento anual médio de 12,8\% entre 2004 e $2014^{3}$. Nesse período, a dívida estudantil tornou-se a segunda mais representativa no endividamento das famílias, atrás somente de hipotecas, ultrapassando aquelas referentes a cartão de crédito e ao segmento automotivo (Figura 1). Segundo dados do Federal Reserve, como pode ser observado na Figura 2, a parcela média da renda disponível das famílias destinada ao serviço da dívida de consumo (dentre elas, a

(3) Esse crescimento representa uma variação real média de $10,7 \%$ ao ano, se os valores forem corrigidos pelo deflator de preços implícito do PIB. 
dívida estudantil) voltou a se elevar a partir de 2013, a despeito da tendência de queda mantida pelo endividamento total e pelo serviço de hipotecas, ambos em proporção da renda das famílias.

\section{Figura 1}

Evolução do saldo de dívida das famílias nos Estados Unidos, excluindo hipotecas.

Valores em bilhões de dólares

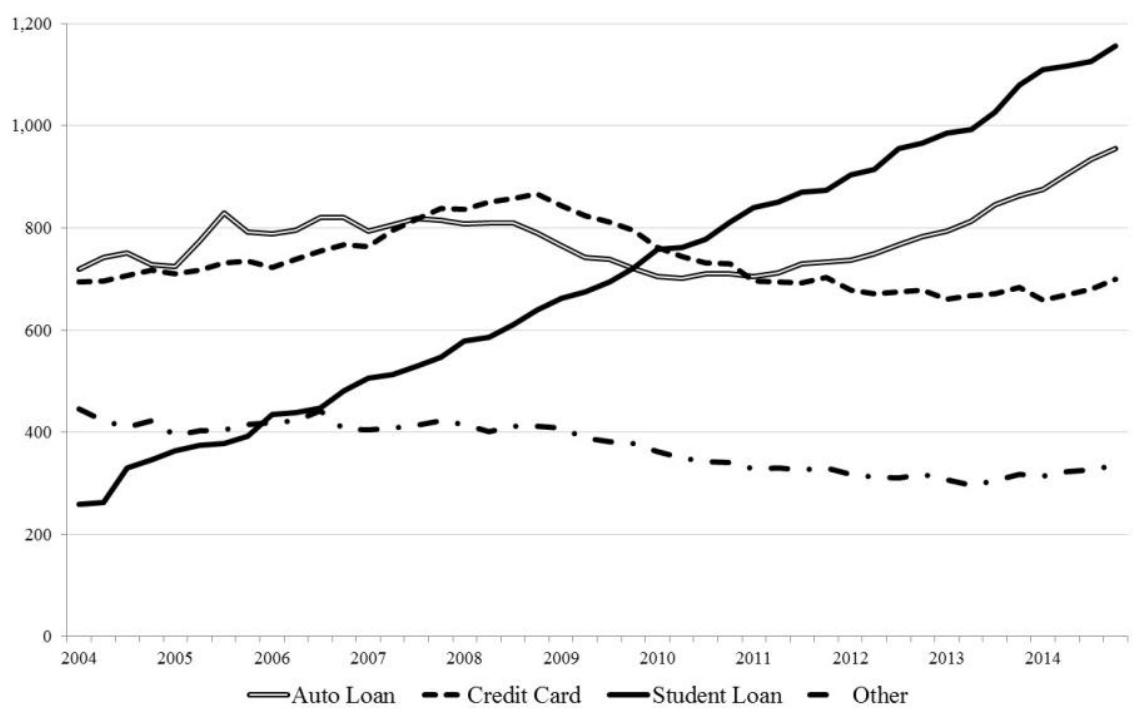

Fonte: Federal Reserve Bank of New York Consumer Credit Panel / Equifax.

Figura 2

Pagamento do serviço da dívida e obrigações financeiras das famílias em porcentagem de sua renda pessoal disponível (com ajuste sazonal)

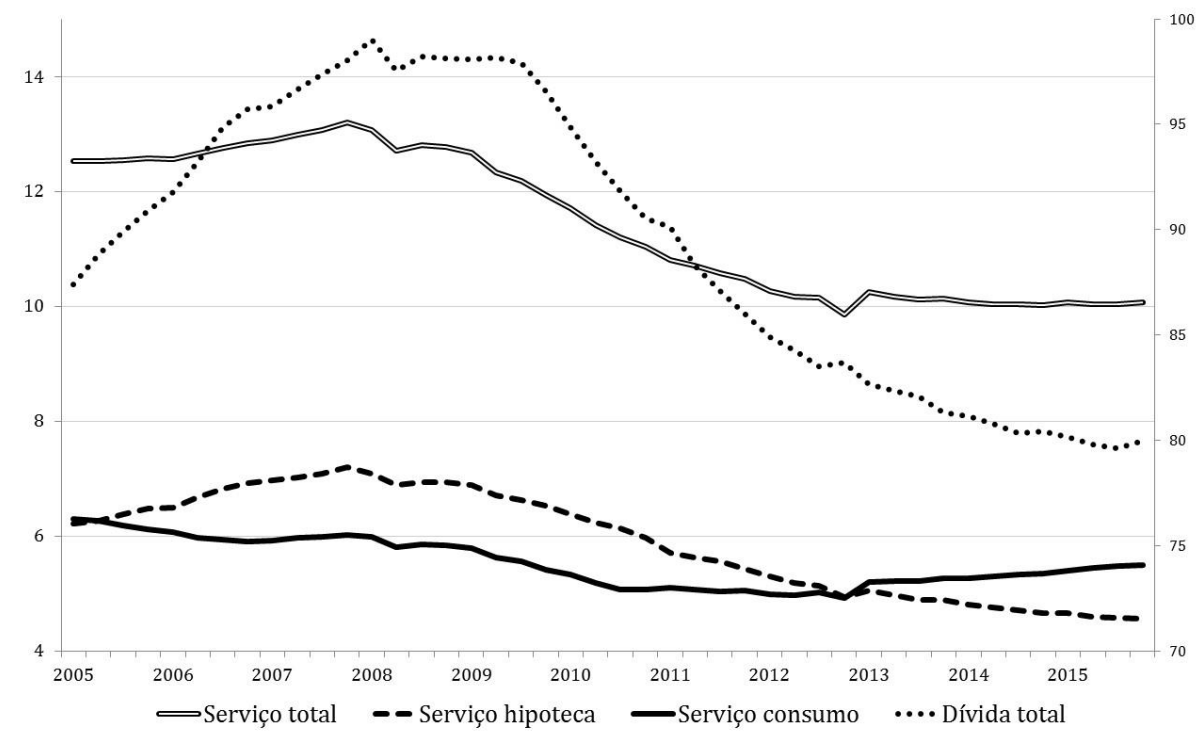

Fonte: Federal Reserve Bank of New York Consumer Credit Panel / Equifax. 
Um dos fatores que explicam esse avanço no endividamento estudantil foi o aumento do número de matrículas em cursos superiores no período. Na comparação entre 2003 e 2013, o número de matrículas no ensino superior elevou-se em 20,5\%, somando 20,4 milhões, sendo o aumento nas instituições públicas $(14,7 \%)$ inferior ao nas privadas $(30,9 \%)$, de maneira que a participação destas no total de matrículas elevou-se de $24,0 \%$ para $27,6 \%$ no período. Dentre as instituições privadas, o crescimento daquelas com fins lucrativos $(132,7 \%)$ foi superior ao das sem fins lucrativos $(18,9 \%)$, embora o número de matrículas (3,97 milhões) ainda seja superior ao das primeiras (1,66 milhões) (IES, 2016). Uma das razões para essa maior demanda pelo ensino superior foi o forte aumento do retorno financeiro desse nível de escolaridade no mercado de trabalho, mesmo quando descontada a elevação observada também dos custos em cursar esse nível de ensino (Locher; MongeNaranjo, 2016).

Ao mesmo tempo em que o número de matrículas elevou-se, a parcela dos alunos que se endividaram para estudar aumentou. No período $2011-12,84,4 \%$ dos estudantes de graduação em cursos de período integral recebiam alguma forma de auxílio financeiro, sendo que 56,7\% dos alunos utilizavam empréstimos estudantis, parcela que tem crescido desde 1999-2000, quando era de 45,6\% (IES, 2016).

\section{Figura 3}

Saldo de dívida de empréstimos estudantis pelo número de tomadores de empréstimo nos Estados Unidos

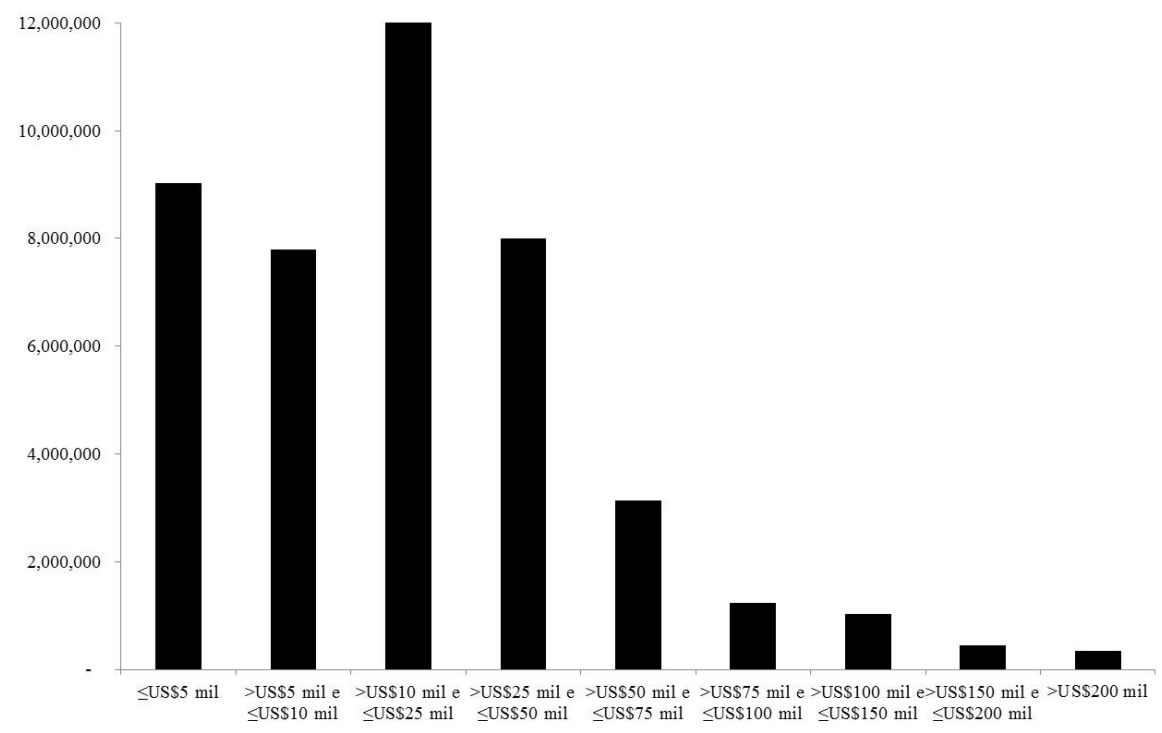

Fonte: Federal Reserve Bank of New York Consumer Credit Panel / Equifax.

O saldo médio da dívida ao final de 2014 era de US\$ 26,7 mil (Figura 3). Segundo o College Board (2015), considerando apenas os alunos e ex-alunos de 
cursos de graduação com duração de 4 anos que utilizaram empréstimos estudantis, a dívida média no período 2013-14 foi de US\$26,9 mil, valor 17,5\% superior, em termos reais, ao observado em 2003-04. A taxa anual de default, a despeito do recuo entre 2011-12 e 2013-14 (de 3.57\% para 3.06\%), tem se elevado em comparação a 2003-04, quando era de 2,36\%, embora em proporção menor que o aumento do saldo médio da dívida (Figura 4).

Figura 4

Evolução da taxa anual de default para empréstimos estudantis nos Estados Unidos

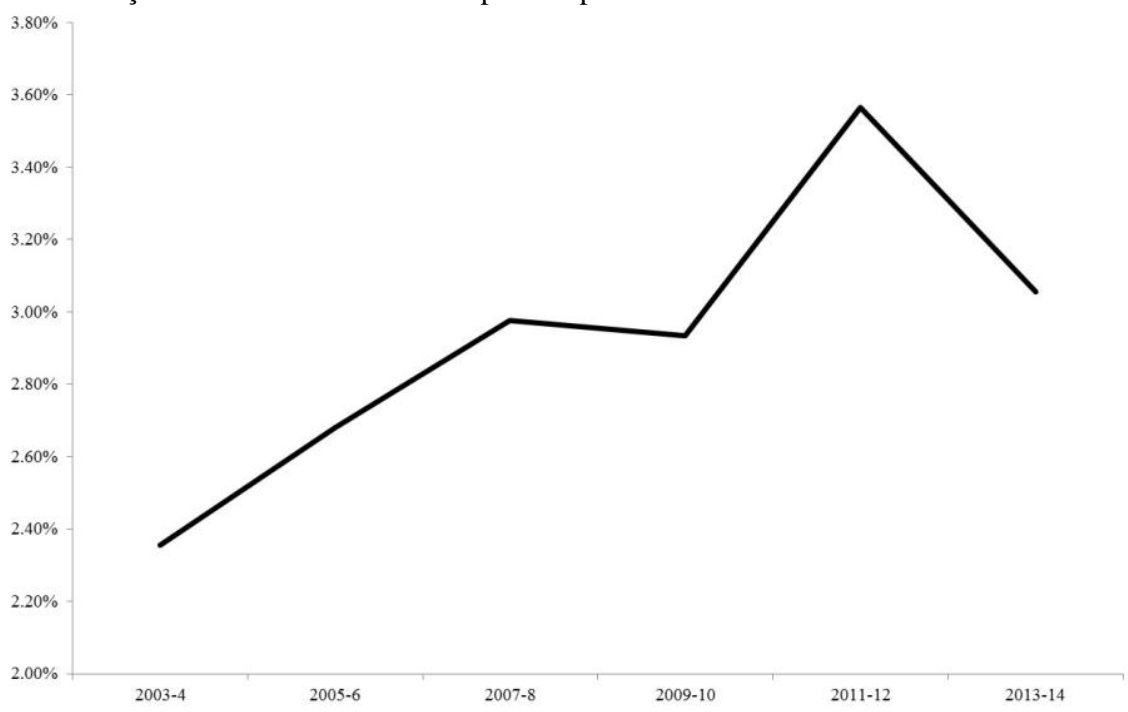

Fonte: Federal Reserve Bank of New York Consumer Credit Panel / Equifax.

Brown et al. (2014, p. 10) mencionam que, apesar de a taxa de inadimplência do endividamento estudantil ser a mais elevada dentre as dívidas referentes ao consumo das famílias, sua forma de cálculo subestima seu nível efetivo. Dessa forma, os autores realizam o cálculo de uma taxa de inadimplência efetiva, excluindo da amostra os estudantes que ainda não estavam no período de repagamento da dívida (dentre esses, por exemplo, aqueles estudantes que ainda não haviam concluído seus estudos). Como resultado, a taxa de inadimplência efetiva foi, em média, o dobro daquela apresentada no Federal Reserve Bank of New York Consumer Credit Panel para os anos de 2004, 2008 e 2012. Com relação àqueles estudantes que conseguiram saldar suas dívidas, Locher e Monge-Naranjo (2016) mencionam que uma parte deles somente conseguiu arcar com o serviço de endividamento utilizando-se de reservas pessoais e de auxílio financeiro das famílias.

Dynarski (2014), embora conteste a opinião de que a situação da dívida estudantil seja alarmante, menciona o aumento no número de estudantes em default após a crise de 2007-8, o que teria levado o governo dos Estados Unidos a propor 
medidas, tais como a redução da taxa de juros, a remissão da dívida estudantil e alterações nas formas de pagamento do saldo devedor, em resposta a uma maior preocupação em relação a uma eventual crise da dívida estudantil. Dentre essas medidas, está a reautorização do Higher Education Act, que criou os Income-Driven Repayment Plans, forma alternativa de pagamento da dívida para os novos tomadores de empréstimos estudantis federais (Akers; Chingos, 2014a). No presente artigo, embora não seja replicada a situação daquele país, representa-se um plano de repagamento da dívida relativamente semelhante aos Income-Driven Repayment Plans, posteriormente comparando-o a uma forma padrão, de maneira a analisar os efeitos teóricos de ambas as formas de pagamento sobre a sustentabilidade do endividamento estudantil.

Os dados referentes à dívida estudantil nos Estados Unidos têm demonstrado sua elevação nos últimos anos, com aumento de seu valor médio e de inadimplência. Dada essa motivação, o presente artigo tem como objetivo verificar determinadas condições econômicas e de financiamento para a sustentabilidade do endividamento familiar em um modelo teórico. Embora, como já apresentado, não se objetive analisar a sustentabilidade do caso utilizado como motivação, serão avaliadas as condições que garantem uma trajetória de redução ou elevação do endividamento das famílias decorrente do financiamento estudantil em um modelo no qual o nível de atividade econômica é determinado pela demanda efetiva agregada.

\section{Literatura relacionada sobre endividamento das famílias}

Dutt (2006, p. 344) destaca duas formas de se analisar a dinâmica da dívida dos trabalhadores. Na primeira abordagem, o comportamento dos trabalhadores, em relação ao seu nível de consumo, definirá a dinâmica de sua dívida. A segunda alternativa, que é considerada pelo autor em seu modelo teórico, trata o consumo como residual, definido após o pagamento dos encargos da dívida. Para a dinâmica do endividamento, Dutt (2006) define um nível desejado para a variação da dívida, que é a função da diferença entre a remuneração dos trabalhadores e o pagamento dos juros da dívida anterior. Já em Dutt (2005), considera-se a existência de um nível desejado de endividamento, também função da renda disponível dos trabalhadores após os encargos da dívida.

Em Setterfield e Kim (2016), a variação no endividamento das famílias é uma função da diferença entre o consumo dos trabalhadores e o seu nível desejado de consumo. Por sua vez, o consumo desejado pelos trabalhadores será uma fração do nível de consumo da classe rentista. Esse comportamento é justificado, segundo argumentam os autores, por um efeito de imitação, por parte das classes de renda mais baixas, do nível de consumo das classes mais elevadas (o efeito denominado "keeping up with the Joneses"). Em sua formulação matemática, Setterfield e Kim (2014) estabelecem para os trabalhadores uma propensão marginal a consumir 
constante sobre a renda, de modo que a parcela não consumida por eles é destinada ao pagamento do serviço da dívida ou à poupança.

Em Setterfield, Kim e Rees (2014), em um modelo relativamente similar a Setterfield e Kim (2014), alterou-se a forma utilizada para abordar o comportamento das famílias em relação ao serviço da dívida. Mantendo a variação no endividamento como consequência do efeito de imitação, Setterfield, Kim e Rees (2014) definem que a propensão marginal a consumir dos trabalhadores atua sobre a renda já líquida do pagamento dos juros da dívida. Essa formulação também é realizada por Kapeller e Schütz (2015), embora esses autores abordem somente os efeitos de curto prazo do endividamento das famílias sobre o nível de atividade.

Barba e Pivetti (2009) também consideram o efeito imitação em sua análise sobre o comportamento do consumo das famílias (além de outros fatores, tais como o maior nível de renda já obtido por aquela classe, a disponibilidade de novos bens e serviços e os bens providos pelo setor público). Ainda que não abordem a interação entre as famílias e as firmas nos equilíbrios de curto e longo prazo, Barba e Pivetti (2009) avaliam condições para a sustentabilidade de seu nível de endividamento a depender de parâmetros, como as taxas de crescimento da renda, de juros e de poupança.

Neste artigo, optar-se-á pela primeira alternativa proposta por Dutt (2006), de maneira que a dinâmica da dívida será residual em relação ao consumo. Essa alternativa garante que, mesmo em situações nas quais o custo com o serviço da dívida é elevado, o nível de consumo dos trabalhadores é estritamente positivo. Como será verificado no modelo teórico, após a discussão da taxonomia Minskyana, existe a possibilidade de que, a depender da dinâmica do endividamento, a remuneração das famílias seja inferior ao serviço da dívida. Dessa maneira, essa forma de abordar a decisão das famílias permite analisar essa situação, caso ela exista.

Serão consideradas duas situações na transição do curto para o longo prazo. Na primeira, a propensão marginal a consumir sobre a renda é constante (como em Setterfield e Kim (2014)), considerando a existência de um conflito distributivo para a definição do salário dos trabalhadores. Essa relação entre o endividamento das famílias e conflito distributivo também foi analisada por Charpe, Flaschel e Proaño (2012), que definem o consumo dos trabalhadores como sendo igual à soma entre sua renda, já líquida dos juros da dívida, e novos endividamentos, que são definidos pelos bancos. A título de ilustração, uma correspondência empírica a essa hipótese para a propensão marginal a consumir é observada nos Estados Unidos para os empréstimos estudantis definidos como Income-Driven Repayment Plans, nos quais a parcela da renda dos estudantes destinada ao pagamento dos juros e da amortização da dívida é constante, podendo ser de $10 \%, 15 \%$ ou $20 \%$ da renda discricionária. 
Na situação 2, diferentemente dos artigos mencionados acima, analisa-se o comportamento da propensão marginal a consumir dos trabalhadores na dinâmica para além do curto prazo, sendo afetada por variações no serviço da dívida, definindo-se uma parcela mínima da renda que deverá ser consumida pelos trabalhadores. Nessa alternativa, as famílias devem arcar, em cada instante, com o pagamento dos juros e com a amortização de determinada porcentagem da dívida, havendo a possibilidade de que seus rendimentos sejam inferiores ao serviço da dívida.

\section{Modelo}

O modelo desenvolvido no presente artigo representa uma economia fechada e sem governo, na qual há uma firma representativa e dois tipos de agente: os capitalistas e os trabalhadores. A firma é responsável por empregar os trabalhadores, remunerar sua mão de obra e destinar todo o seu lucro aos capitalistas. Considera-se que, anteriormente ao período inicial do modelo, os trabalhadores obtiveram empréstimos estudantis, concedidos pelos capitalistas, para elevar seu nível de escolaridade. Assim, no primeiro período considerado no modelo, os trabalhadores herdam um nível de capital humano mais elevado e uma dívida estudantil que acarretará no pagamento de juros e de amortização. Esse estoque de capital humano já estará incorporado na produtividade e no salário dos trabalhadores no primeiro período do modelo.

Supõe-se que a mão de obra é homogênea (isto é, todos os trabalhadores apresentam o mesmo nível de capital humano e, portanto, de produtividade). A partir do instante inicial do modelo, não será analisada a decisão por novos investimentos no capital humano dos trabalhadores. Como será apresentado na Seção 3.2, somente serão permitidos novos empréstimos a esse agente para a rolagem de seu endividamento original. Assim, enfatiza-se, a análise a ser realizada compreende a sustentabilidade do endividamento das famílias, sendo comparadas duas formas de repagamento dos empréstimos estudantis vigentes nos Estados Unidos, sem acumulação contínua de capital humano.

Dessa maneira, pretende-se verificar, sob determinadas condições tratadas no modelo, quais os impactos do pagamento dos juros e da amortização da dívida estudantil, contraída pelos trabalhadores junto aos capitalistas, sobre a economia representada e se essa dívida inicial apresenta-se sustentável. Para a análise dos resultados, considera-se sustentável a dívida que se apresentar estável a longo prazo, podendo o seu valor ser nulo, ou não. Embora não se trate aqui da decisão a respeito de novos investimentos em escolarização, considera-se que a abordagem aqui utilizada apresenta relevância ao analisar se a dívida estudantil, que se encontra atualmente em patamar elevado (como pôde ser observado na seção anterior), poderá 
ser saldada em um horizonte relevante. Dessa maneira, aborda-se aqui somente o período posterior à aquisição da dívida.

\subsection{Firma representativa}

A firma representativa utiliza dois fatores de produção, capital físico e mão de obra, e produz um único bem homogêneo, sendo que a função de produção apresenta coeficientes fixos. O nível de emprego da mão de obra $(L)$ nessa economia é determinado pela demanda agregada $(Y)$ e pela produtividade dessa mão de obra $\left(\sigma_{L}\right)$ :

$$
L=\frac{Y}{\sigma_{L}}
$$

Por simplificação, como a mão de obra é homogênea e não haverá a possibilidade de novos investimentos em capital humano do trabalhador, supõe-se que $\sigma_{L}=1$. A função de investimento será definida com base no nível de utilização da capacidade instalada $(u)$, de forma que a taxa de crescimento do estoque de capital físico será:

$$
\begin{aligned}
& \frac{I}{K}=g_{K}=\alpha_{0}+\alpha_{1} u \\
& \alpha_{0}>0, \alpha_{1}>0
\end{aligned}
$$

Nessa dependência da taxa de crescimento do estoque de capital físico em relação ao nível de utilização da capacidade produtiva, na linha de um efeito acelerador, seguimos Rowthorn (1981) e Dutt (1984, 1990), os quais, por sua vez, seguem Steindl (1952). Por simplicidade, a taxa de depreciação no modelo é nula para ambas as formas de capital (físico e humano). O nível de utilização da capacidade produtiva depende da razão entre o produto efetivo $(Y)$ e o produto resultante da utilização total dos fatores $\left(Y_{f c}\right)$, que é função do estoque de capital $(K)$. Supõe-se que a produtividade máxima do capital tem valor $\sigma_{K}=1$, com que:

$$
u=\frac{Y}{Y_{f c}}=\frac{Y}{K}
$$

Supõe-se que a dinâmica da demanda efetiva é tal que o nível de atividade econômica será sempre inferior àquele correspondente à plena utilização da capacidade instalada, isto é, $u<1$. A renda agregada dessa economia será dividida entre as duas classes mencionadas, sendo $V$ o salário real dos trabalhadores e $\Pi$ o 
montante de lucros, destinados aos capitalistas ${ }^{4}$. Dessa forma, as parcelas de cada grupo na renda somam 1 , sendo $\omega$ referente ao grupo de trabalhadores e $\pi$ à parcela dos lucros. Como $\sigma_{L}=1$, tem-se que $\omega=V^{5}$. Logo:

$$
1=\omega+\pi
$$

\subsection{Dívida dos trabalhadores}

Na economia representada, os trabalhadores apresentam uma dívida $D$, que acarretará o pagamento de juros (a uma taxa $r$ ) e de sua amortização (a uma taxa $\varphi$ ) aos capitalistas. Contudo, o pagamento dos encargos da dívida é residual em relação ao consumo, de maneira que somente uma parcela $(1-\beta)$ da renda dos trabalhadores será destinada a essa finalidade. Assim, a depender do rendimento do trabalhador e das taxas de juros e de amortização, a dívida estudantil pode ser reduzida ou elevada em cada período, sendo sua variação $(\dot{D}=d D / d t)$ definida abaixo:

$$
\begin{gathered}
\dot{D}=-\varphi D+[(\varphi+r) D-(1-\beta) \omega Y]=r D-(1-\beta) \omega Y \\
\varphi>0, \quad r>0, \quad \beta \in(0,1)
\end{gathered}
$$

Vale ressaltar que, neste modelo, os trabalhadores somente podem tomar novas dívidas caso sua renda seja insuficiente para arcar com os juros e com a amortização do principal da dívida, decorrente do financiamento estudantil, visto que não se considera a possibilidade de novos investimentos em capital humano. Esses novos empréstimos, resultantes da rolagem da dívida, também serão contraídos pela família junto aos capitalistas, implicando o pagamento de juros e da amortização às mesmas taxas vigentes para a dívida inicial, que permanecerão constantes no curto e no longo prazos.

\subsection{Equilíbrio no curto prazo}

Nesta seção será apresentado o equilíbrio de curto prazo nessa economia, no qual permanecem constantes a distribuição de renda, o endividamento dos trabalhadores e o estoque de capital. Neste caso, o nível de utilização da capacidade $(\boldsymbol{u})$ ajusta-se para que a oferta agregada equipare-se à demanda efetiva agregada. As funções de consumo para os trabalhadores e para os capitalistas são definidas, nessa ordem, por:

$$
C_{\omega}=\beta V Y
$$

(4) Esse montante não inclui os valores referentes ao pagamento do serviço da dívida. $\omega=\frac{V}{\sigma_{L}}=V(5)$
$504 \quad$ Economia e Sociedade, Campinas, v. 27, n. 2 (63), p. 493-523, maio-agosto 2018. 


$$
\begin{aligned}
& C_{\pi}=c_{\pi}(\pi Y+r D) \\
& c_{\pi} \in(0,1)
\end{aligned}
$$

A relação entre os capitalistas e os trabalhadores segue Kapeller e Schütz (2015), segundo os quais a criação de crédito é endógena, e novos empréstimos não são decorrentes de fundos emprestáveis. Dessa maneira, a amortização da dívida não eleva o poder de compra dos capitalistas, ao passo que o pagamento de juros tem esse efeito. Os autores demonstram a consistência entre fluxos e estoques desse modelo em Kapeller e Schütz (2014) ${ }^{6}$.

O nível de renda dessa economia será determinado pela demanda efetiva agregada, que equivale à soma entre os níveis de consumo de cada grupo e o investimento das firmas:

$$
Y=C_{\omega}+C_{\pi}+I
$$

A satisfação da igualdade acima resulta no nível de utilização da capacidade no equilíbrio de curto prazo, a partir de (1), (2), (6), (9) e (10), fixados os estoques de capital físico, a dívida estudantil e a remuneração dos trabalhadores:

$$
u^{*}=\frac{\alpha_{0}+c_{\pi} r d}{1-\alpha_{1}-c_{\pi}-\left(\beta-c_{\pi}\right) V}=\frac{\alpha_{0}+c_{\pi} r d}{\Omega}
$$

sendo $d=D / K$ uma medida do endividamento como proporção do estoque de capital.

A condição de estabilidade Keynesiana para essa economia, de acordo com a qual a poupança responde mais intensamente a uma variação na utilização da capacidade que o investimento, será:

$$
\Omega=1-\alpha_{1}-c_{\pi}-\left(\beta-c_{\pi}\right) V>0
$$

Os efeitos marginais da dívida, da remuneração dos trabalhadores e da propensão marginal a consumir sobre o nível de atividade econômica são dados, respectivamente, por:

$$
\begin{aligned}
& \frac{\partial u}{\partial d}=\frac{c_{\pi} r}{\Omega}>0 \\
& \frac{\partial u}{\partial V}=\frac{\left(\alpha_{0}+c_{\pi} r d\right)\left(\beta-c_{\pi}\right)}{(\Omega)^{2}}
\end{aligned}
$$

(6) Resumidamente, o aumento da dívida dos trabalhadores, para que não seja decorrente de fundos emprestáveis, representa uma elevação dos ativos dos capitalistas. De maneira análoga, a amortização de parte dessa dívida reduz o ativo disponível pelos capitalistas, sem representar aumento de seu poder de compra, para que seja garantida a consistência entre fluxos e estoques. 


$$
\frac{\partial u}{\partial \beta}=\frac{\left(\alpha_{0}+c_{\pi} r d\right) V}{(\Omega)^{2}}>0
$$

É importante destacar que o impacto positivo do endividamento sobre o nível de atividade deve-se ao fato de o consumo dos trabalhadores tratar do pagamento dos juros e da amortização da dívida como residual, de forma que o único impacto da dívida sobre a demanda agregada consiste em seu efeito no consumo dos capitalistas, por meio do pagamento de juros. Já o efeito de variações no salário sobre a utilização da capacidade depende de qual classe apresenta propensão marginal a consumir superior, sendo positivo caso os trabalhadores destinem uma parcela de sua renda ao consumo superior a $c_{\pi}$, o que tende a ser o caso típico.

A partir das equações (1), (2), (15) e (16), pode-se observar que os efeitos de $d, V$ e $\beta$ sobre o nível de utilização da capacidade e sobre a taxa de crescimento do estoque de capital apresentarão os mesmos sentidos. Dado que a função (2) depende somente de $u$, a direção (embora não a magnitude) do efeito de variações em $d, V$ e $\beta$ sobre $u$ e $g_{K}$ será a mesma. Assim, nesse cenário, elevações do endividamento estudantil e da propensão marginal a consumir dos trabalhadores terão impacto positivo sobre o nível de atividade a curto prazo, ao passo que o efeito do salário real dos trabalhadores dependerá de sua propensão marginal a consumir em comparação à dos capitalistas.

\subsection{Taxonomia Minskyana}

Em Minsky (1986), são apresentadas três definições que caracterizam a situação financeira de uma firma no que tange à adequação de seu fluxo de caixa aos seus compromissos financeiros: hedge, especulativa e Ponzi. Em Minsky (1992), é ressaltada a possibilidade de se analisar o impacto da situação financeira de outros agentes, tais como as famílias e o setor público, sobre a dinâmica econômica, utilizando as mesmas classificações para a relação entre seus rendimentos e suas dívidas.

Lima e Meirelles (2007) também utilizam a taxonomia Minskyana ao analisarem a instabilidade financeira de um modelo teórico no qual se avalia o fluxo de caixa das firmas e a sua capacidade de pagamento do serviço de sua dívida. A dinâmica do modelo a longo prazo é avaliada em um sistema de equações diferenciais referentes à variação do endividamento e da taxa de juros sobre os empréstimos, sendo que esta última é função de um mark-up definido pelo setor bancário sobre a taxa base, estabelecida exogenamente pela autoridade monetária ${ }^{7}$. A adaptação da taxonomia à situação financeira das famílias é realizada abaixo.

(7) No presente modelo, dadas as características dos empréstimos estudantis nos Estados Unidos, por exemplo, consideram-se constantes as taxas de juros e de amortização. 
Segundo Minsky (1986, p. 232), a situação hedge é caracterizada pela existência de fluxos de caixa operacionais compatíveis com os compromissos financeiros da unidade credora. Essa descrição equivale, adaptando-a ao modelo apresentado, a uma situação na qual a parcela destinada ao pagamento dos encargos da dívida é superior ou igual ao valor dos juros e da amortização da dívida:

$$
(1-\beta) V Y \geq(\varphi+r) D \Rightarrow(1-\beta) V u \geq(\varphi+r) d
$$

Nota-se que a condição de sustentabilidade dessa dívida não dependerá somente do salário recebido, mas também do valor de equilíbrio de $u$, que responde à demanda agregada dessa economia. Uma situação intermediária, em que é possível arcar com os juros da dívida, mas não com sua amortização, é a situação especulativa, na qual se espera "que os fluxos de caixa operacionais (ou financeiros) possam ser transitoriamente menores que os serviços das dívidas em alguns períodos, porém suficientes para cobrir pelo menos a parte referente a juros" (Minsky, 1986, p. 232). Formalmente:

$$
r d \leq(1-\beta) V u<(\varphi+r) d
$$

A última situação (Ponzi) caracteriza-se pela impossibilidade de arcar com o valor total dos juros da dívida. Assim, "nas unidades Ponzi [destaque do autor], os custos do financiamento superam as receitas de modo que o saldo devedor aumenta com o tempo" (Minsky, 1986, p. 233). Essa situação é representada formalmente por:

$$
(1-\beta) V u<r d
$$

Fixados os valores para as demais variáveis, essas três situações são apresentadas na Figura 5 em relação à dívida e ao salário dos trabalhadores:

Figura 5

Curvas de demarcação para a taxonomia Minskyana

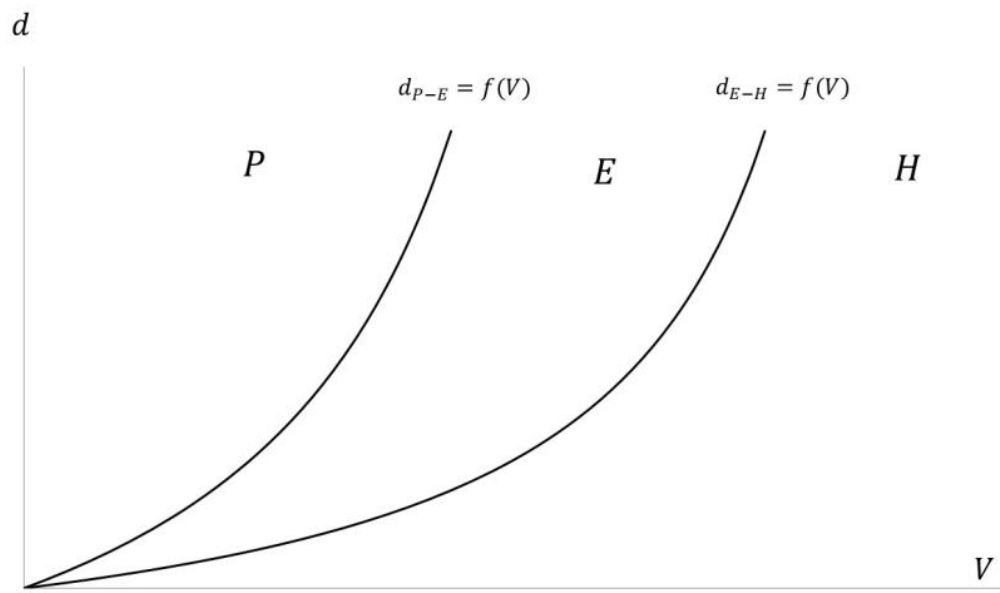

Economia e Sociedade, Campinas, v. 27, n. 2 (63), p. 493-523, maio-agosto 2018. 
As curvas de demarcação que dividem as três regiões são:

$$
\begin{aligned}
& d_{P-E}=\frac{(1-\beta) \alpha_{0} V}{r A-r \beta\left(1-c_{\pi}\right) V} \\
& d_{E-H}=\frac{(1-\beta) \alpha_{0} V}{(r+\varphi) A-\left[\left(\beta-c_{\pi}\right) \varphi+r \beta\left(1-c_{\pi}\right)\right] V}
\end{aligned}
$$

sendo $A=1-c_{\pi}-\alpha_{1}$.

A região H da Figura 5 compreende a situação hedge. Nela, os rendimentos obtidos pela classe endividada são suficientes para arcar com o serviço da dívida. A região E indica a situação especulativa, e a região $\mathrm{P}$ a situação Ponzi. A partir das equações (19) e (20), verifica-se que as curvas de demarcação (21) e (22) encontramse, respectivamente, nas regiões especulativa e hedge. É importante destacar que essa é uma análise de curto prazo da situação das famílias. A dinâmica dessa economia a longo prazo pode fazer com que o trabalhador representativo migre de uma região a outra, de forma que esse trabalhador representativo pode encontrar-se em uma situação hedge em curto prazo e tornar-se Ponzi em longo prazo, e vice-versa. A evolução desse endividamento é tratada nas próximas seções.

Segundo Minsky (1995, p. 198), em períodos economicamente favoráveis, a estrutura de endividamento das famílias, tal qual a das firmas, altera-se no sentido de elevar a parcela da renda destinada ao serviço dessa dívida, levando, ao final, a uma ampliação da fragilidade financeira. Embora as condições de financiamento do investimento e do consumo, em termos de taxas de juros e de amortização, sejam consideradas constantes e exogenamente determinadas no presente artigo, um dos mecanismos descritos por Minsky (1995) poderá ser analisado no modelo desenvolvido na próxima seção: a destinação de parte da renda das famílias ao pagamento do serviço da dívida tem impacto negativo sobre a demanda efetiva agregada, podendo acarretar impacto desfavorável ao nível de investimentos. Essa redução da demanda, se verificada, reduz a renda das famílias, prejudicando sua condição de arcar com o próprio serviço desse endividamento.

\section{Situação 1: equilíbrio no longo prazo quando $d$ e $V$ variam}

Para se analisar a dinâmica do endividamento na transição para o longo prazo, será assumida a possibilidade de variação do nível de capital físico, da dívida e do salário dos trabalhadores. O objetivo, ao incluir essa última variável no modelo, é tratar, de certa forma, a questão da remuneração dos trabalhadores no modelo de endividamento estudantil, que é recorrente na literatura sobre o tema. O valor desse salário será definido por um conflito distributivo entre os trabalhadores e os capitalistas, obedecendo a seguinte equação: 


$$
\dot{V}=\gamma\left(V_{\omega}-V\right)
$$

Sendo $V_{\omega}$ o salário desejado pelos trabalhadores e $\gamma$ a intensidade da convergência entre o salário vigente e o salário desejado. A abordagem de um conflito distributivo para a determinação do salário real dos trabalhadores, em um modelo com endividamento das famílias, também foi realizada por Charpe, Flaschel e Proaño (2012). No artigo mencionado, os autores realizam uma análise sobre instabilidade financeira em um modelo teórico no qual existe a possibilidade de restrição de crédito, a depender do desempenho do setor bancário em comparação a seu lucro de longo prazo. Nele, considera-se que o nível de consumo dos trabalhadores será sempre superior à sua renda, sendo esse excedente no consumo financiado por novos empréstimos (implicando valor positivo da dívida no equilíbrio de longo prazo). Dados os propósitos do presente artigo, o modelo teórico aqui representado não considera o comportamento do setor financeiro, sobretudo, pois analisa-se apenas a sustentabilidade de um endividamento preexistente sob diferentes formas de repagamento, sem verificar as decisões da família em relação a novos empréstimos ${ }^{8}$.

A variação do salário dos trabalhadores dependerá da diferença entre o salário vigente $(V)$ e o salário desejado pelos trabalhadores $\left(V_{\omega}\right)$, sendo que esse último é definido por ${ }^{9}$ :

$$
\begin{aligned}
& V_{\omega}=\varepsilon_{0}+\varepsilon_{1} u \\
& \varepsilon_{0}>0, \varepsilon_{1}>0
\end{aligned}
$$

Verifica-se que, quanto mais próxima a economia em relação ao pleno emprego, maior será o salário esperado pelos trabalhadores. A intensidade da

(8) Nota-se que, aqui, dados os propósitos do presente artigo, não é necessária a definição de hipóteses para que a dívida analisada apresente valor positivo no equilíbrio de longo prazo, pois permite-se a possibilidade de que o valor total dessa dívida seja eventualmente saldado. Todavia, como um valor negativo para o endividamento dos trabalhadores representaria, efetivamente, um empréstimo destes aos capitalistas, a análise realizada compreenderá apenas valores não negativos dessa dívida.

(9) Dadas as equações (1) e (4), para que o nível de utilização da capacidade permaneça constante no equilíbrio para $d$ e $V$, supõe-se que a taxa de crescimento da oferta de trabalho $(n)$ é endógena e determinada por $n=g_{K}$. Definida essa hipótese, verifica-se, então, que $u$ é uma representação adequada para a taxa de emprego $(e)$, sendo definida pela razão entre a mão de obra empregada e a disponível $(N)$ :

$$
e=\frac{L}{N}=\frac{L}{Y} \frac{K}{N} \frac{Y}{K}=\frac{1}{\sigma_{L}} \frac{K}{N} u
$$

Tendo-se definido $n=g_{K}$ e $\sigma_{L}=1$, caso se suponha que a fração entre o montante de capital físico e a quantidade disponível de mão de obra também é constante e normalizada em 1, por exemplo, obtém-se que $e=u$. Por essa razão, a análise realizada para o equilíbrio de curto prazo será baseada no nível de utilização da capacidade, mantendo-se em mente, porém, a igualdade entre esse nível e a taxa de emprego. 
convergência entre o salário vigente e o salário desejado $(\gamma)$ e os parâmetros da função do salário desejado pelos trabalhadores ( $\varepsilon_{0}$ e $\varepsilon_{1}$ ) apresentam valores positivos, constantes e exogenamente determinados ${ }^{10}$. Dessa forma, as variações do endividamento dos trabalhadores e de seu salário, definidas a partir de (7), (23) e (24), são dadas, respectivamente, por:

$$
\begin{aligned}
& \dot{d}=r d-(1-\beta) V u-g_{K} d \\
& \dot{V}=\gamma\left(\varepsilon_{0}+\varepsilon_{1} u-V\right)
\end{aligned}
$$

Por simplicidade no tratamento matemático, supõe-se que $\alpha_{0}=\varepsilon_{0}=0$. Em equilíbrio, considerando que o nível de utilização da capacidade sempre estará no equilíbrio definido em (13):

$$
\begin{aligned}
& \dot{d}=0 \Rightarrow d^{*}=\frac{A-\left(1-c_{\pi}\right) \beta V^{*}}{c_{\pi} \alpha_{1}} \\
& \dot{V}=0 \Rightarrow d^{*}=\frac{A V^{*}-\left(\beta-c_{\pi}\right)\left(V^{*}\right)^{2}}{\varepsilon_{1} c_{\pi} r}
\end{aligned}
$$

A matriz Jacobiana desse sistema de equações contém os seguintes elementos:

$$
J_{\left(d^{*}, V^{*}\right)}=\left(\begin{array}{cc}
r-(1-\beta) V^{*} \frac{\partial u^{*}}{\partial d^{*}}-\alpha_{1}\left(u^{*}+d^{*} \frac{\partial u^{*}}{\partial d^{*}}\right) & -(1-\beta)\left(u^{*}+V^{*} \frac{\partial u^{*}}{\partial V^{*}}\right)-\alpha_{1} d^{*} \frac{\partial u^{*}}{\partial V^{*}}<0 \\
\gamma \varepsilon_{1} \frac{\partial u^{*}}{\partial d^{*}}>0 & \gamma\left(\varepsilon_{1} \frac{\partial u^{*}}{\partial V^{*}}-1\right)
\end{array}\right)
$$

\section{Utilizando os valores em equilíbrio:}

(10) Considere que o nível de preços definido pela firma seja baseado em uma equação kaleckiana do tipo $P=z W$ (lembrando que $\sigma_{L}=1$ ), sendo $z>1$ o fator de mark-up (um mais o mark-up) da firma e $W$ o salário nominal. Assim, a taxa de variação (proporcional) do nível de preços será $\hat{P}=\hat{z}+\hat{W}$, em que usamos o símbolo "^" para denotar a taxa de variação proporcional da variável em questão $(\operatorname{logo}$, por exemplo, $\hat{W}=\dot{W} / W)$. Visto que o salário real dos trabalhadores é determinado por $V=W / P$, para que as variações no salário nominal obtidas pelos trabalhadores no conflito distributivo sejam as mesmas que afetam as taxas de variação do salário real (o que implica $\hat{P}=0$ ), supõe-se que $\hat{V}=-\hat{z}$, isto é, o sucesso dos trabalhadores na barganha salarial representada em (23)-(24) (a qual concretamente ocorre, não obstante, em termos nominais) se traduz em uma redução no fator de mark-up. Assim, normalizando $P=1$, tem-se que $W$ é igual ao salário real $(V)$ e, dado que o presente modelo está especificado em termos reais, não abordamos explicitamente a distinção entre variáveis nominais e reais. O objetivo dessa hipótese é não abordar, no modelo, de maneira explícita, o comportamento da variável, nível de preços e de sua taxa de variação proporcional, que é a taxa de inflação, haja vista seu impacto potencial sobre a dinâmica do endividamento e sobre a taxa de juros real do financiamento, algo que, embora relevante, não se encontra no escopo do presente artigo. 


$$
\begin{gathered}
\frac{\partial \dot{d}}{\partial d^{*}}=r-\frac{(1-\beta) V^{*} c_{\pi} r}{\Omega^{*}}-\frac{2 \alpha_{1} c_{\pi} r d^{*}}{\Omega^{*}}=-\alpha_{1} u^{*}<0 \\
\frac{\partial \dot{d}}{\partial V^{*}}=-\frac{u^{*}}{\Omega^{*}}\left[A(1-\beta)+\alpha_{1}\left(\beta-c_{\pi}\right) d^{*}\right]<0 \\
\frac{\partial \dot{V}}{\partial d^{*}}=\frac{\gamma V^{*}}{d^{*}}>0 \\
\frac{\partial \dot{V}}{\partial V^{*}}=\frac{\gamma}{\Omega^{*}}\left[2\left(\beta-c_{\pi}\right) V^{*}-A\right]
\end{gathered}
$$

$\operatorname{Det}\left(J_{\left(d^{*}, V^{*}\right)}\right)=\frac{c_{\pi} r \gamma}{\left(\Omega^{*}\right)^{2}}\left[\alpha_{1} \Omega^{*} d^{*}+A(1-\beta) V^{*}\right]>0$

A análise da equação (34) indica que apresentará sinal negativo caso o valor de equilíbrio para $V$ seja inferior a $A /\left[2\left(\beta-c_{\pi}\right)\right]$. Vale ressaltar que esse valor definido é inferior àquele que satisfaz a condição (14), que equivale a $V_{\Omega}<A /\left(\beta-c_{\pi}\right)$. Na Figura 6, que ilustra o sistema de equações analisado, esse valor para $V_{\max }$ é representado pela curva tracejada. O destaque a esse valor é explicado no Apêndice A. Na Figura 6 também são representadas as curvas de demarcação que definem as regiões da taxonomia Minskyana ${ }^{11}$. Como apresentado no Apêndice A, um dos fatores que definirá a estabilidade do equilíbrio será o poder de barganha dos trabalhadores. A Figura 6a apresenta um caso no qual $\varepsilon_{1}$ é relativamente reduzido, implicando em $J_{2,2}<0$. Nesse caso, o equilíbrio registrado será estável, com $\operatorname{Det}\left(J_{\left(d^{*}, V^{*}\right)}\right)>0$ e $\operatorname{Tr}\left(J_{\left(d^{*}, V^{*}\right)}\right)<0$. Tudo o mais constante, caso $\beta>2 c_{\pi} /\left(1+c_{\pi}\right)$, um aumento do poder de barganha dos trabalhadores (representado na Figura 6b) pode levar ao caso em que o sinal de (34) é positivo, o que torna o sistema propenso à instabilidade.

(11) Com $\alpha_{0}=0$ e $\varepsilon_{0}=0$, as regiões da taxonomia Minskyana são definidas por:

$$
\begin{aligned}
V_{P-E} & =\frac{\sigma_{L} A}{\beta\left(1-c_{\pi}\right)} \\
V_{E-H} & =\frac{\sigma_{L}(\varphi+r) A}{\beta r\left(1-c_{\pi}\right)+\varphi\left(\beta-c_{\pi}\right)}
\end{aligned}
$$

Sejam $V_{\max }$ o valor de $V$ que maximiza (29) e $V_{V}$ e $V_{d}$ definidos quando $d=0$ em, respectivamente, $\dot{V}=0$ e $\dot{d}=0$. As seguintes relações, representadas na Figura 6, podem ser matematicamente verificadas:

$V_{\text {max }}<V_{d}=V_{P-E}<V_{E-H}<V_{V}=V_{\Omega}$ 
Esse resultado é mais bem detalhado no Apêndice A. Aparentemente contraintuitivo, ele indica que, mesmo em uma economia cuja função de investimento caracteriza-se por tender a fazer com que a utilização da capacidade seja wage-led, como apresenta-se em (2), um aumento do poder de barganha dos trabalhadores, embora reduza o nível de endividamento e eleve a parcela dos salários na renda no equilíbrio de longo prazo, pode tornar esse equilíbrio mais propenso à instabilidade. Ressalta-se que, embora uma elevação da parcela dos salários na renda tenha impacto positivo sobre a capacidade de pagamento das famílias (e sobre o nível de atividade, inclusive), a redução na dívida de equilíbrio atua em sentido contrário, reduzindo o nível de atividade, como verificado em (15).

Figura6

Diagrama de Fase para o sistema $\{\dot{d}, \dot{V}\}$

Figura 6a

Figura $6 \mathrm{~b}$

$\varepsilon_{1}$ relativamente baixo

$\varepsilon_{1}$ relativamente elevado

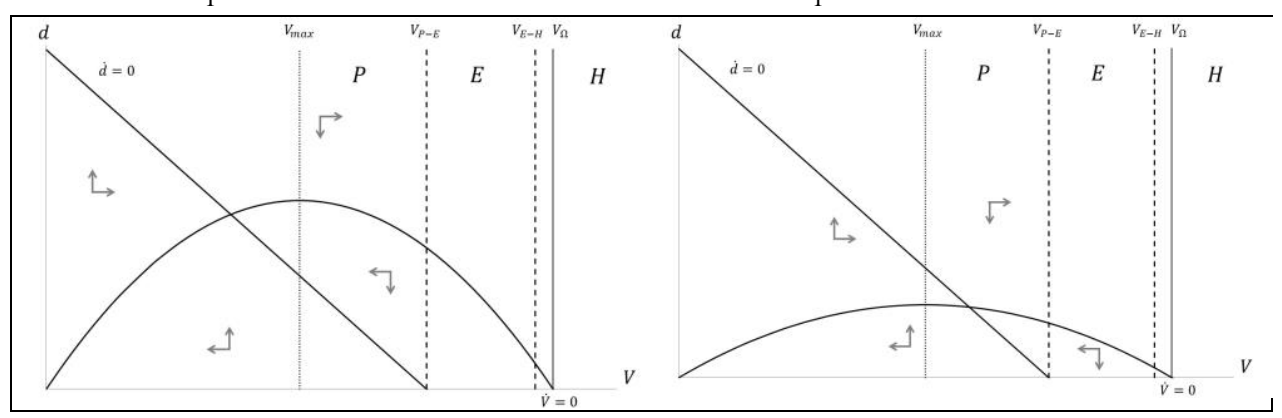

No Apêndice B são apresentadas as Situações 2 e 3 no caso em que os capitalistas poupam toda a sua renda. Nele, verifica-se que essa situação torna-se mais propensa à instabilidade na ausência de consumo dos capitalistas. Se na presença do consumo dos capitalistas $J_{2,2}<0$ implicava a estabilidade do sistema, na ausência, esse equilíbrio será caracterizado por um ponto de sela, de modo que a convergência ao equilíbrio somente ocorrerá no caso em que se está no ramo estável da sela. Esse fato é explicado, dado o pagamento do serviço da dívida, pois a existência de $c_{\pi}>0$ representa uma reinjeção de recursos na economia, o que eleva a demanda efetiva agregada e o nível de atividade econômica e, consequentemente, a capacidade de pagamento da dívida pelos trabalhadores.

Verifica-se também que, dados os domínios economicamente relevantes para os parâmetros e a condição (14), o equilíbrio será em uma região na qual o rendimento das famílias será inferior ao serviço total da dívida, de modo que a estabilidade de $d$ somente é garantida pelo crescimento no estoque de capital e, consequentemente, do produto econômico decorrente da utilização total dos fatores. Esse resultado justifica a discussão realizada anteriormente sobre a taxonomia 
Minskyana, ao demonstrar que, embora o endividamento representado possa apresentar um equilíbrio estável, nele as famílias se encontrarão em uma situação financeira Ponzi.

Esse resultado é consequência da forma de repagamento do endividamento: definida uma parcela da renda dos trabalhadores que será destinada ao pagamento do serviço do empréstimo, a rolagem dessa dívida, se não houver restrições a ela, tem impacto positivo sobre o nível de atividade, visto seu efeito sobre o consumo dos trabalhadores e dos capitalistas (para estes, por conta de seu consumo de parcela dos juros). Assim, no caso em que há a estabilidade, partindo-se de uma situação de Hedge ou Especulativa, a diminuição do nível de endividamento, resultante dessas condições financeiras, tem impacto negativo sobre o nível de atividade, reduzindo os rendimentos dos trabalhadores e, consequentemente, levando essa economia a uma situação Ponzi.

\section{Situação 2: equilíbrio no longo prazo quando $d$ e $\beta$ variam}

Como mencionado anteriormente, o impacto positivo do endividamento sobre o nível de atividade na equação (15) deve-se à hipótese de que, para os trabalhadores, o pagamento de juros e da amortização da dívida é residual, de modo que aumentos da dívida não têm impacto negativo sobre a demanda agregada. $\mathrm{Na}$ situação aqui apresentada, será considerada uma forma de repagamento do empréstimo na qual a propensão marginal a consumir dos trabalhadores varia conforme o nível de dívida, da seguinte forma:

$$
\begin{aligned}
& \dot{\beta}=\frac{1-\beta_{\text {min }}}{1+(r+\varphi) d}-\left(\beta-\beta_{\text {min }}\right) \\
& \beta \in\left(\beta_{\text {min }}, 1\right]
\end{aligned}
$$

Assim, na ausência de dívida, o conjunto de trabalhadores consumirá toda a sua renda, e, conforme a dívida é elevada, maior será a parcela da renda dedicada ao pagamento de seu serviço, havendo uma parcela mínima da renda, definida exogenamente, que o trabalhador deve consumir. Neste caso, o impacto de um aumento do endividamento sobre o nível de atividade não será mais necessariamente positivo na transição para o longo prazo, dado seu efeito negativo sobre a propensão marginal a consumir dos trabalhadores. Mantendo constante a distribuição da renda e assumindo novamente $\alpha_{0}=\varepsilon_{0}=0$, o sistema de equações a ser avaliado na dinâmica de longo prazo será definido pelas equações (26) e (39). Em equilíbrio, têm-se os seguintes resultados e a matriz Jacobiana abaixo:

$$
\dot{\beta}=0 \Rightarrow \beta^{*}=\frac{1+\beta_{\min }(r+\varphi) d^{*}}{1+(r+\varphi) d^{*}}, d^{*}=\frac{1-\beta^{*}}{\left(\beta^{*}-\beta_{\min }\right)(r+\varphi)}
$$




$$
\begin{gathered}
\dot{d}=0 \Rightarrow \beta^{*}=\frac{A-\alpha_{1} c_{\pi} d^{*}}{V\left(1-c_{\pi}\right)}, d^{*}=\frac{A-V\left(1-c_{\pi}\right) \beta^{*}}{\alpha_{1} c_{\pi}} \\
J_{\left(d^{*}, \beta^{*}\right)}=\left(\begin{array}{cc}
-\alpha_{1} u^{*}<0 & -\frac{\left(1-c_{\pi}\right) V u^{*}}{c_{\pi}}<0 \\
-\frac{(r+\varphi)\left(\beta^{*}-\beta_{\text {min }}\right)^{2}}{\left(1-\beta_{\min }\right)}<0 & -1<0
\end{array}\right)
\end{gathered}
$$

Sendo o determinante da matriz Jacobiana definido por:

$\operatorname{Det}\left(J_{\left(d^{*}, \beta^{*}\right)}\right)=\frac{r}{\left(1-\beta_{\min }\right) \Omega^{*}}\left\{A\left(1-\beta_{\text {min }}\right)-\left(1-c_{\pi}\right) V\left[\beta^{*}-\left(\beta^{*}\right)^{2}+\beta^{*}-\beta_{\text {min }}\right]\right\}$

O sistema de equações $\{\dot{d}, \dot{\beta}\}$ é apresentado na Figura 7. Embora não inclua o conflito distributivo, verifica-se que esse sistema é estável, com $\operatorname{Tr}\left(J_{\left(d^{*}, \beta^{*}\right)}\right)<0$ e $\operatorname{Det}\left(J_{\left(d^{*}, \beta^{*}\right)}\right)>0^{12}$.

Figura 7

Diagrama de Fase para o sistema $\{\dot{d}, \dot{\beta}\}$

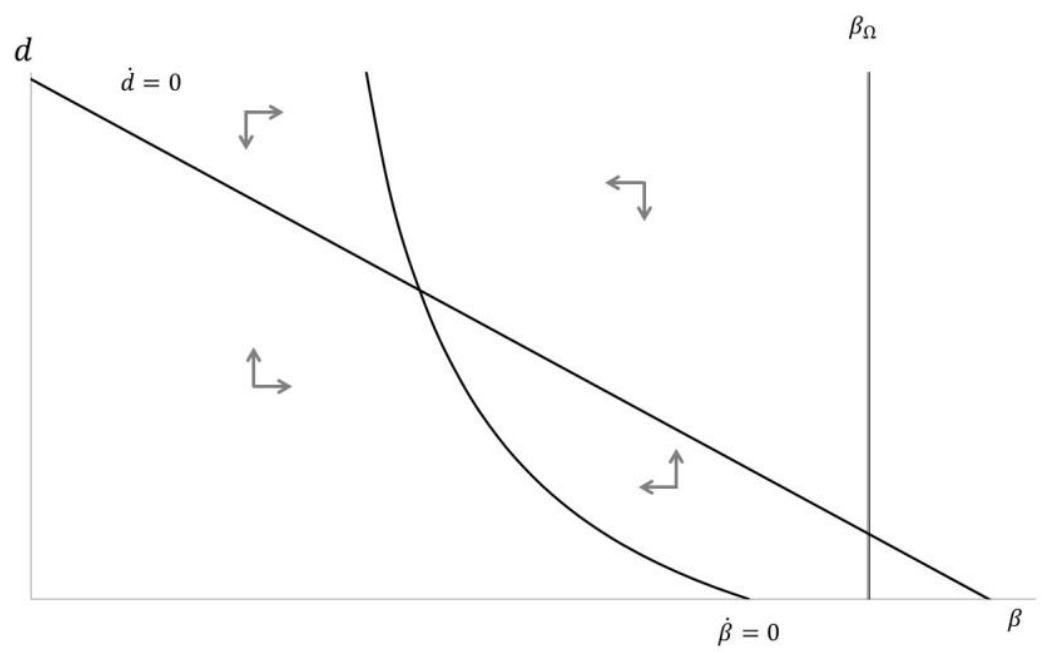

(12) O resultado $\operatorname{Det}\left(J_{\left(d^{*} \beta^{*}\right)}\right)>0$ é obtido a partir das condições (40) e (45), sendo a última definida a seguir. Para que a condição de estabilidade Keynesiana, apresentada na equação (14), seja válida para $\beta=1$, devese observar: $\Omega=1-\alpha_{1}-c_{\pi}-\left(\beta-c_{\pi}\right) V>0 \Rightarrow \beta_{\Omega}<\frac{A+c_{\pi} V}{V}$ 
No Apêndice B, todavia, mostra-se que a estabilidade desse sistema depende, também, do consumo dos capitalistas. No caso em que $c_{\pi}=0$, o equilíbrio de $\{\dot{d}, \dot{\beta}\}$ será caracterizado por um ponto de sela e, novamente, a sustentabilidade do endividamento dependerá de que a alocação esteja no ramo estável da sela. Em relação a outras variáveis, nota-se que elevações em $\beta_{\text {min }}$ alteram a inclinação da curva definida por $\dot{\beta}=0$ na Figura 7 , reduzindo a dívida de equilíbrio e aumentando $\beta^{*}$. Apesar de contraintuitiva, a existência de um patamar mínimo de propensão a consumir evita uma redução relativamente mais acentuada da demanda efetiva para níveis relativamente elevados de dívida, o que tem efeito positivo sobre a capacidade de pagamento de seu serviço pelos trabalhadores. Efeito similar é observado para elevações da parcela dos trabalhadores na renda agregada $V$ (dado seu impacto na curva $\dot{d}=0$ ), que favorecem a capacidade de pagamento em longo prazo, implicando em $d^{*}$ relativamente mais baixo e uma propensão a consumir maior.

Essa forma de repagamento do empréstimo tem um potencial efeito favorável sobre a situação financeira dos trabalhadores ${ }^{13}$. Na Situação 1 , a redução do endividamento afetava desfavoravelmente o nível de atividade. Neste caso, parte desse efeito negativo é mitigado por uma elevação da propensão marginal a consumir dos trabalhadores, decorrente dessa redução da dívida, tendo efeito positivo sobre o nível de atividade, o que compensa parte do impacto do menor nível de endividamento sobre a dinâmica macroeconômica ${ }^{14}$. No entanto, é possível verificar que, dadas as condições supostas para os parâmetros, o equilíbrio neste caso também se encontra na região Ponzi ${ }^{15}$.

(13) Uma flexibilização da forma de repagamento baseada na renda (income-based repayment) também é defendida, por exemplo, por Locher e Monge-Naranjo (2016), que avaliam a sua vantagem no que concerne a problemas informacionais, dado o maior incentivo da forma de repagamento analisada na Situação 1 para que o tomador de dívida não declare a totalidade de sua remuneração.

(14) Também foi realizada a análise de estabilidade para o caso que combina as Situações 1 e 2, isto é, considerando a existência de conflito distributivo e a dinâmica da propensão marginal a consumir dos trabalhadores como função de seu nível de endividamento. Ao se analisarem as condições de estabilidade de Routh-Hurtwitz para o caso em que $\partial \dot{V} / \partial V<0$, a estabilidade do sistema em três dimensões $\{\dot{d}, \dot{V}, \dot{\beta}\}$ é facilmente verificada. Todavia, para $\partial \dot{V} / \partial V>0$, após uma análise preliminar, observou-se que as condições de estabilidade são bastante restritivas e de complexa verificação analítica, comprometendo a obtenção de resultados bem definidos. Desse modo, optou-se por não incluir esses resultados na presente versão do artigo.

(15) Embora a Figura 7 não inclua as regiões da taxonomia Minskyana, o Apêndice C aborda essa questão, apresentando, inclusive, uma representação gráfica da taxonomia Minskyana para o sistema $\{\dot{d}, \dot{\beta}\}$ a partir de uma simulação com base em valores plausíveis dos parâmetros e variáveis exógenas. 


\section{Conclusão}

Este artigo teve como objetivo despertar atenção à questão do endividamento estudantil em modelos macrodinâmicos liderados pela demanda efetiva agregada. A análise dos dados de empréstimos estudantis nos Estados Unidos indicou uma elevação em seus saldos de dívida e na inadimplência nos últimos anos. Embora o financiamento estudantil apresente importância para que mais indivíduos possam cursar o ensino superior, alerta-se para o aumento das dívidas das famílias que esse mecanismo tem gerado. Propôs-se, aqui, realizar uma análise da sustentabilidade do endividamento que compreendesse não os diferenciais de salário que a elevação da escolaridade proporciona (embora o salário real homogêneo possa variar ao longo do tempo como resultado de um conflito distributivo), mas determinadas condições macroeconômicas para seu pagamento afetadas por essa dívida. Foram comparadas duas formas de repagamento dos empréstimos. Na primeira, a parcela da renda destinada ao serviço da dívida era constante e, em uma segunda abordagem, foram permitidas variações na propensão marginal a consumir das famílias em resposta a variações dos encargos desse endividamento. Como resultado, verificou-se, no contexto do presente modelo simplificado, a existência de situações nas quais essa dívida não será sustentável, a depender de fatores como as condições de repagamento do empréstimo estudantil, o poder de barganha dos trabalhadores no conflito distributivo e a propensão marginal a consumir dos capitalistas. Esses resultados do modelo formal, considerando-se sua robustez lógico-teórica, certamente fornecem mais um aporte de conhecimento relevante em análises de experiências concretas em âmbito nacional e/ou de programas específicos.

\section{Bibliografia}

AKERS, B.; CHINGOS, M. M. Student loan safety nets: estimating the costs and benefits of income-based repayment. Brown Center on Education Policy, Brookings Institution, 2014a.

AKERS, B.; CHINGOS, M. M. Is a student loan crisis on the horizon? Brown Center on Education Policy, Brookings Institution, 2014b.

AVERY, C.; TURNER, S. Student loans: do college students borrow too much-or not enough? Journal of Economic Perspectives, v. 26, n. 1, p. 165-192, 2012.

BARBA, A.; PIVETTI, M. Rising household debt: Its causes and macroeconomic implications-a long-period analysis. Cambridge Journal of Economics, n. 33, n. 1, p. 113-137, 2009.

BECKER, G. S. Human capital: a theoretical and empirical analysis with special reference to education. New York: Columbia University Press, 1964. 
BROWN, M. et al. Measuring student debt and its performance. Federal Reserve Bank of New York, 2014. (Staff Reports, n. 668).

CARD, D. The causal effect of education on earnings. In: ASHENFELTER, O. C.; CARD, D. Handbook of labor economics. v. 3, part. A. North-Holland: Elsevier, 1999. p. 1801-1863.

CARNEIRO, P.; HECKMAN, J. J.; VYTLACIL, E. J. Estimating marginal returns to education. The American Economic Review, v. 101, n. 6, p. 2754-2781, 2011.

CHARPE, M.; FLASCHEL, P.; PROAÑO, C. R. Income distribution, credit rationing and households' debt. Metroeconomica, v. 63, n. 3, p. 458-492, 2012.

COLLEGE BOARD. Trends in college pricing 2015. New York: College Board, 2015.

DUTT, A. K. Stagnation, income distribution and monopoly power. Cambridge Journal of Economics, v. 8, n. 1, 1984.

DUTT, A. K. Growth, distribution and uneven development. Cambridge: Cambridge University Press, 1990.

DUTT, A. K. Consumption, debt and growth. In: SETTERFIELD, M. (Ed.). Interactions in analytical political economy. Armonk, NY: M.E. Sharpe, 2005. p. 155-178.

DUTT, A. K. Maturity, stagnation and debt: a Steindlian approach. Metroeconomica, n. 57, p. 339-364, 2006.

DYNARSKI, S.; KREISMAN, D. Loans for educational opportunity: making borrowing work for today's students. The Hamilton Project, 2013.

DYNARSKI, S. An economist's perspective on student loans in the United States. Economic Studies at Brookings, 2014. (ES Working Paper Series).

IES - Institute of Education Science. Digest of education statistics 2014. 50 ${ }^{\text {th }}$ ed. Washington: National Center for Education Statistics, 2016.

KAPELLER, J.; SCHÜTZ, B. Debt, boom, bust: a theory of Minsky-Veblen cycles. Journal of Post Keynesian Economics, v. 36, n. 4, p. 781-814, 2014.

KAPELLER, J., SCHÜTZ, B. Conspicuous consumption, inequality and debt: the nature of consumption driven profit-led regimes. Metroeconomica, v. 66, n. 1, p. 51-70, 2015.

LIMA, G. T.; MEIRELLES, A. J. A. Macrodynamics of debt regimes, financial instability and growth. Cambridge Journal of Economics, v. 31, n. 4, p. 563-580, 2007. 
LOCHER, L.; MONGE-NARANJO, A. Student loans and repayment: theory, evidence and policy. In: HANUSHEK, E. A.; MACHIN, S.; WOESSMAN, L. Handbook of the economics of education, v. 5. North-Holland: Elsevier, 2016. p. 397-478.

MINSKY, H. P. The financial instability hypothesis. The Jerome Levy Economics Institute, 1992. (Working Paper, n. 74).

MINSKY, H. P. Financial factors in the economics of capitalism. Journal of Financial Services Research, v. 9, p. 197-208, 1995.

MINSKY, H. P. (1986) Estabilizando uma economia instável. 2 ed. Trad. de José Maria Alves da Silva. Osasco, SP: Novo Século Editora, 2013.

OREOPOULOS, P.; SALVANES, K. G. Priceless: the nonpecuniary benefits of schooling. Journal of Economic Perspectives, v. 25, n. 1, p. 159-184, 2011.

ROWTHORN, B. Demand, real wages and economic growth. Thames Papers in Political Economy, Autumn, 1981.

SETTERFIELD, M.; KIM, Y. K. Debt servicing, aggregate consumption, and growth. Structural Change and Economic Dynamics, v. 36, p. 22-33, 2016.

SETTERFIELD, M.; KIM, Y. K.; RESS, J. Inequality, debt servicing, and the sustainability of steady state growth. New School for Social Research, Department of Economics, 2014. (Working Paper, 1404).

STEINDL, J. Maturity and stagnation in American capitalism. New York: Monthly Review Press, 1952. 


\section{Apêndice A}

Neste apêndice serão analisadas as condições para que o traço da matriz Jacobiana do sistema $\{\dot{d}, \dot{V}\}$ seja positivo ou negativo. Dado que o determinante dessa matriz é positivo, o resultado $\operatorname{Tr}\left(J_{\left(d^{*}, V^{*}\right)}\right)>0$ tornará esse sistema instável. O caso $\operatorname{Tr}\left(J_{\left(d^{*}, V^{*}\right)}\right)<0$, ao contrário, garantirá a estabilidade. Utilizando as equações (28) e (29), dados os domínios dos parâmetros, o valor economicamente relevante para $V^{*}$ será definido por:

$$
V^{*}=\frac{\left[\alpha_{1} A+\varepsilon_{1} r\left(1-c_{\pi}\right) \beta\right]-\sqrt{\Delta}}{2 \alpha_{1}\left(\beta-c_{\pi}\right)}
$$

Sendo

$$
\Delta=\left[\alpha_{1} A+\varepsilon_{1} r\left(1-c_{\pi}\right) \beta\right]^{2}-4 \varepsilon_{1} r A \alpha_{1}\left(\beta-c_{\pi}\right)
$$

A partir de (31) e (34), o traço da matriz Jacobiana será:

$$
\operatorname{Tr}\left(J_{\left(d^{*}, V^{*}\right)}\right)=\frac{-(r+\gamma) A+\left[\beta r\left(1+c_{\pi}\right)-2 \gamma\left(\beta-c_{\pi}\right)\right] V^{*}}{\Omega^{*}}
$$

Nota-se que uma condição suficiente para $\operatorname{Tr}\left(J_{\left(d^{*}, V^{*}\right)}\right)<0$ é a equação (34) apresentar sinal negativo, o que implica em (46) ser inferior a $A /\left[2\left(\beta-c_{\pi}\right)\right]$. Por essa razão, o valor para $V_{\max }$, apresentado na nota de rodapé 14, é destacado na Figura 6. A condição mencionada é representada por:

$$
\alpha_{1} A+2 r \varepsilon_{1}\left[-\beta\left(1+c_{\pi}\right)+2 c_{\pi}\right]>0
$$

Desse modo, $\beta<2 c_{\pi} /\left(1+c_{\pi}\right)$ é uma condição suficiente à estabilidade desse sistema. Caso contrário, deve-se observar $\varepsilon_{1}<\frac{\alpha_{1} A}{2 r\left[\beta\left(1+c_{\pi}\right)-2 c_{\pi}\right]}$ para que $J_{2,2}<0$.

Dado o resultado acima, verifica-se que uma propensão marginal a consumir superior a $2 c_{\pi} /\left(1+c_{\pi}\right)$ e um poder de barganha dos trabalhadores acima de $\frac{\alpha_{1} A}{2 r\left[\beta\left(1+c_{\pi}\right)-2 c_{\pi}\right]}$ tornam o sistema mais propenso à instabilidade, ao resultarem em $J_{2,2}>0$. 


\section{Apêndice B}

Neste Apêndice são representadas as Situações 1 e 2 no caso em que os capitalistas poupam toda a sua renda (isto é, $c_{\pi}=0$ ). Diferentemente do que foi assumido nas seções, aqui define-se $\alpha_{0}, \varepsilon_{0} \neq 0$. A equação (13) será:

$$
u^{*}=\frac{\alpha_{0}}{1-\alpha_{1}-\beta V}=\frac{\alpha_{0}}{\Omega}
$$

Utilizando as equações (26) e (27), o equilíbrio do sistema de equações $\{\dot{d}, \dot{V}\}$ é apresentado abaixo:

$$
\begin{gathered}
\dot{V}=0 \Rightarrow \beta\left(V^{*}\right)^{2}-\left(1-\alpha_{1}+\varepsilon_{0} \beta\right) V^{*}+\left[\varepsilon_{1} \alpha_{0}+\varepsilon_{0}\left(1-\alpha_{1}\right)\right]=0 \\
\dot{d}=0 \Rightarrow d^{*}=\frac{(1-\beta) \alpha_{0} V^{*}}{r \Omega^{*}-\alpha_{0}\left(1-\beta V^{*}\right)}
\end{gathered}
$$

Assumindo-se uma combinação dos parâmetros de modo a garantir $d^{*}, V^{*}, \Omega^{*}>0$, a matriz Jacobiana apresenta os seguintes elementos:

$$
J_{\left(d^{*}, V^{*}\right)}=\left(\begin{array}{cc}
\frac{(1-\beta) V^{*} \alpha_{0}}{d^{*} \Omega^{*}}>0 & -\frac{(1-\beta)}{\left(\Omega^{*}\right)^{2}}\left[\beta \alpha_{0} V^{*}+\alpha_{0} \Omega^{*}\right]-\frac{\alpha_{1} \alpha_{0} \beta d^{*}}{\left(\Omega^{*}\right)^{2}}<0 \\
0 & \frac{\gamma\left[\beta\left(V^{*}-\varepsilon_{0}\right)-\Omega^{*}\right]}{\Omega^{*}}
\end{array}\right)
$$

A depender do sinal de $J_{2,2}$, o equilíbrio pode ser caracterizado das seguintes maneiras:

$$
\begin{gathered}
J_{2,2}>0 \Rightarrow \operatorname{tr}\left(J_{\left(d^{*}, V^{*}\right)}\right)>0, \operatorname{Det}\left(J_{\left(d^{*}, V^{*}\right)}\right)>0 \Rightarrow \text { Equilíbrio instável } \\
J_{2,2}<0 \Rightarrow \operatorname{Det}\left(J_{\left(d^{*}, V^{*}\right)}\right)<0 \Rightarrow \text { Ponto de sela }
\end{gathered}
$$

A Situação 2, que representa o sistema $\{\dot{d}, \dot{\beta}\}$, apresenta a seguinte matriz Jacobiana na ausência de consumo dos capitalistas, utilizando-se os valores de equilíbrio:

$$
J_{\left(d^{*}, \beta^{*}\right)}=\left(\begin{array}{cc}
\frac{\left(1-\beta^{*}\right) V \alpha_{0}}{d^{*} \Omega^{*}}>0 & -\frac{V \alpha_{0}}{\left(\Omega^{*}\right)^{2}}\left[-1+\alpha_{1}+V+\alpha_{1} d^{*}\right] \\
-\frac{(r+\varphi)\left(\beta^{*}-\beta_{\min }\right)}{1+(r+\varphi) d^{*}}<0 & -1<0
\end{array}\right)
$$


Sustentabilidade do endividamento estudantil em uma macrodinâmica liderada pela demanda

Logo:

$$
\operatorname{Tr}\left(J_{\left(d^{*}, \beta^{*}\right)}\right)=-(1-r)-\frac{\alpha_{0}\left(1-V \beta^{*}\right)}{\Omega^{*}}<0
$$

$\operatorname{Det}\left(J_{\left(d^{*}, \beta^{*}\right)}\right)=-\frac{\left(1-\beta^{*}\right) V \alpha_{0}}{\left(\Omega^{*}\right)^{2}\left[1+(r+\varphi) d^{*}\right]}\left\{\alpha_{1}[1-(r+\varphi)] d^{*}+V\left(1-\beta^{*}\right)+(r+\varphi)\left(1-V \beta^{*}\right) d^{*}\right\}<0$ (58)

A matriz Jacobiana desse sistema de equações indica que seu equilíbrio será um ponto de sela ${ }^{16}$.

(16) É importante destacar que a característica desse equilíbrio é, em parte, consequência da definição implícita de um valor mínimo para a taxa de juros, de modo a garantir $d^{*}$ positivo, como pode ser verificado no denominador da equação (52). 


\section{Apêndice C}

Na Situação 2, a Figura 7 não inclui as regiões da taxonomia Minskyana. A razão para esse fato consiste na complexidade topológica para a realização dessa análise para o caso em questão. Diferentemente de $V$, a variável $\beta$ tem um efeito negativo e um positivo sobre a capacidade de pagamento da dívida dos trabalhadores, representada nas equações (18)-(20). Embora aumentos em $\beta$ elevem o nível de atividade, implicam uma redução da parcela da renda dos trabalhadores destinada ao pagamento do serviço da dívida. A verificação da superposição e do impacto relativo desses efeitos depende dos parâmetros e do nível de endividamento.

A título de ilustração, a Figura 8 representa essa taxonomia Minskyana para a Situação 2. Para que a verificação das curvas de demarcação fosse mais clara, incluiu-se novamente $\alpha_{0} \neq 0$ (o que também alterou a curva $\dot{d}=0$ em comparação à Figura 7). Nela, pode-se notar que a superposição dos efeitos positivo e negativo de variações em $\beta$ sobre a capacidade de pagamento da dívida é alterada a partir de um determinado nível de endividamento. Assim, para um $d$ relativamente baixo, a ordem das regiões Minskyanas seria, da esquerda para a direita da figura, Ponzi-Especulativo-Hedge, de maneira que o impacto positivo de elevações em $\beta$ sobre o nível de atividade sobreporia seu efeito negativo. Nesse caso, um aumento em $\beta$ poderia levar em curto prazo, tudo o mais constante, o trabalhador a uma região Hedge. Entretanto, para valores elevados dessa dívida, a magnitude relativa desses efeitos altera-se, de forma que a ordem das regiões Minskyanas inverte-se, passando a ser Hedge-Especulativo-Ponzi.

\section{Figura 8}

Diagrama de Fase para o sistema $\{\dot{d}, \dot{\beta}\}$, com $\alpha_{0} \neq 0$ e a taxonomia Minskyana.

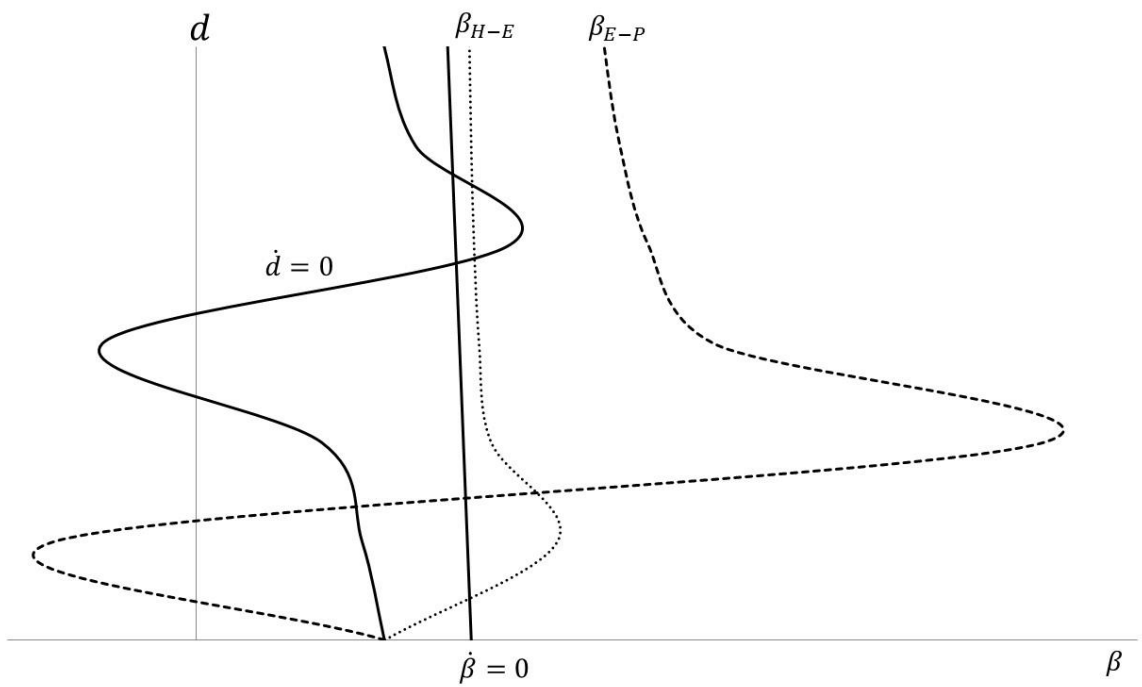


Parâmetros: $\quad \alpha_{0}=0.05 ; \alpha_{1}=0.1 ; c_{\pi}=0.2 ; r=0.1 ; \varphi=0.1, V=0.6 ; \beta_{\min }=0.3$

Alterações no valor dos parâmetros, respeitadas as várias restrições paramétricas estabelecidas ao longo do artigo, modificam o posicionamento das curvas de demarcação e o equilíbrio de longo prazo, embora a inversão das regiões Minskyanas a partir de determinado nível de $d$ siga sendo verificada. 